\title{
Efficacy of 635nm Red Low-Level Laser on Nociceptive Musculoskeletal Pain Compared to NSAIDS, Opioids, and Other Light Sources
}

\author{
Jacob Januskewski ${ }^{1}$, Chris Bromley ${ }^{2}$, Cesar A Lara ${ }^{3}$, Kirk Gair ${ }^{4}$, Brandon Brock ${ }^{5}$, Leonid Polishuk ${ }^{6}$ and Travis \\ Sammons $^{7 *}$
}

${ }^{1}$ Department of Neurological Surgery, Brain and Spine Clinic, USA

${ }^{2}$ Podiatrist, Premier Medical Group, USA

${ }^{3}$ Weight Loss \& Wellness, USA

${ }^{4}$ Gair Laser Chiropractic, USA

${ }^{5}$ Brock Integrative Medicine, USA

${ }^{6}$ Polishuk Physical Therapy, Wellness \& Fitness, USA

${ }^{7}$ Erchonia Corporation, USA

Submission: October 28, 2020; Published: November 09, 2020

*Corresponding author: Travis Sammons, Erchonia Corporation, 650 Atlantis Road, Melbourne, FL 32904, USA

\begin{abstract}
Background: According to the World Health Organization, musculoskeletal conditions comprise more than 150 diagnoses affecting muscles, bones, joints and related tissues including tendons and ligaments. The use of $635 \mathrm{~nm}$ red low-level laser has demonstrated beneficial effects for treating a range of painful musculoskeletal conditions including low back pain, plantar fasciitis, neck, and shoulder pain.

Methods: Data is compiled from six IRB-approved clinical trials which assessed the efficacy of $635 \mathrm{~nm}$ lasers for reducing pain arising from chronic conditions. These included five randomized, placebo-controlled studies and one randomized comparative study.

Results: Among subjects in the active treatment group, there was a 45.4\% mean decrease in VAS scores compared to a $15.1 \%$ mean decrease among sham-treated subjects $(\mathrm{p}<0.0001)$. The active treatment group also documented significant improvement in range of motion, oswestry disability index, and foot function index.
\end{abstract}

Conclusion: Based on the data the Food and Drug Administration (FDA) cleared the first low-level laser for the indication as adjunctive use in providing temporary relief of nociceptive musculoskeletal pain.

Keywords: Low-level laser therapy; Musculoskeletal pain; Low back pain; Chronic pain; Clinical trial; lllt

\section{Introduction}

According to the World Health Organization, musculoskeletal conditions comprise more than 150 diagnoses affecting muscles, bones, joints and related tissues including tendons and ligaments. ${ }^{1}$ The most common and disabling conditions are osteoarthritis, back and neck pain, fractures associated with bone fragility, injuries, and systemic inflammatory conditions such as rheumatoid arthritis [1]. It has been estimated that 107.5 million people experience musculoskeletal disease annually in the United States [2]. As the prevalence of musculoskeletal conditions is substantially higher among the elderly, the overall prevalence is likely to increase due to this growing population. The aggregate costs among persons with musculoskeletal diseases including direct healthcare costs and lost wages was estimated to be $\$ 980$ billion annually during 2012-2014 [2]. According to the Medical Expenditure Panel Survey, the annual cost of pain management was greater than the annual costs of heart disease, cancer, and diabetes [3]. Low back pain is one of the most prevalent musculoskeletal conditions requiring treatment and among the most common conditions presenting to primary care physicians [4]. According to one systematic review, the 1-year prevalence of 
low back pain ranged from 22 to $65 \%$, and lifetime prevalence ranged from 11 to $84 \%$ [5].

Traditional pharmacotherapy for managing low back pain has consisted of nonsteroidal anti-inflammatory drugs (NSAIDs) which inhibit cyclo-oxygenase (Cox), thereby preventing the formation of inflammatory prostaglandins [4]. Overall, NSAIDs are superior to placebo for treating chronic low back pain with no significant difference in pain reduction between Cox-2 selective and traditional NSAID [6]. Unfortunately, their use can be limited by gastrointestinal and cardiac toxicity $[7,8]$, although newer Cox-2 selective inhibitors (celecoxib, rofecoxib) are safer than traditional NSAIDs (naproxen, ibuprofen) [4]. A promising alternative to pharmacotherapy is the use of low-level laser therapy (LLLT). In June 2019, The Food and Drug Administration (FDA) cleared the first low-level laser (Erchonia ${ }^{\circledR}$ FX-635 ${ }^{\text {тм }}$ ) for the indication as adjunctive use in providing temporary relief of nociceptive musculoskeletal pain (K190572). The 510(k) clearance was based on numerous completed studies that demonstrated effectiveness for treating various anatomical areas affected by chronic musculoskeletal pain. The objective of the following review is to analyze data from six studies totaling 419 subjects assessing immediate efficacy, long-term durability, and functional index improvement using red $635 \mathrm{~nm}$ (Erchonia Corp.) nonthermal laser devices for the treatment of chronic musculoskeletal conditions.

\section{Methods}

Data is compiled from six IRB-approved clinical trials which assessed the efficacy of $635 \mathrm{~nm}$ lasers for reducing pain arising from chronic painful conditions. These included five randomized, placebo-controlled studies and one randomized comparative study [9-12]. Several of these studies have been previously published [13-16]. The devices utilized $635 \mathrm{~nm}$ red laser diodes ranging from 5 - 17.5mw(Erchonia Corporation, Melbourne, FL). The variable hertz feature of each device is a pulsed wave, defined as containing a preprogrammed series of breaks. The devices internal mechanics collect light emitted from each laser diode which is processed through a proprietary patented lens to produce a line generated beam. The total energy delivered was between $4-10.5$ joules to the treatment area. The sham devices applied light-emitting diodes (LED) light of the same color when activated.

The assessed treatment areas included chronic neck and shoulder pain, low back pain and heel pain caused by plantar fasciitis. Each condition has previously received a respective FDA indication based on submitted clinical data (K012580, K132940, K180197). Adult male and female subjects were enrolled in each study. The total study sample $(N=419)$ included subjects that received active treatment $(n=234)$ and sham treatment $(n=185)$ as indicated in Table 1.

Table 1: Sample Size Across Trials.

\begin{tabular}{|c|c|c|c|c|c|c|}
\hline & Neck \& Shoulder \#1 & Neck \& Shoulder \#2 & Neck \& Shoulder \#3 & Plantar Fasciitis & Low Back \#1 & Low Back \#2 \\
\hline Active & 50 & 43 & 44 & 37 & 31 & 29 \\
\hline Sham & 50 & 43 & - & 32 & 31 & 29 \\
\hline Total & 100 & 86 & 44 & 69 & 62 & 58 \\
\hline
\end{tabular}

For each clinical trial, pain severity was assessed by subjects using a 0-100 Visual Analog Scale (VAS). The VAS is widely used across a broad range of populations and clinical settings and has been well-accepted as a generic pain measure for many years [17]. The following analysis is based on the change in mean pretreatment subject VAS scores at study endpoint. The relevance of endpoint evaluation was consistent across all trials. The individual subject treatment success criterion in each trial was preestablished, as stipulated by the Food and Drug Administration, as a $\geq 35 \%$ decreased VAS pain scores between treatment and sham group. .

Five trials recorded post-treatment VAS pain scores from 24 hours to 12 months. As the timing of post-treatment pain evaluations was inconsistent, longitudinal VAS pain scores are reported for two time periods that enabled combining data from two or more studies for evaluation. These time points were 2 to 4 weeks and 2 to 4 months post-treatment. Subject satisfaction with pain relief was evaluated by subjects using a 5-point Likert scale (Table 2).
Table 2: Study Outcome Satisfaction Rating at Study Endpoint.

\begin{tabular}{|c|c|c|}
\hline & $\begin{array}{c}\text { Active Group } \\
\text { (n=109) }\end{array}$ & $\begin{array}{c}\text { Sham Group } \\
\text { (n=61) }\end{array}$ \\
\hline Very Satisfied & $37(34)$ & $\mathbf{n}(\mathbf{\%})$ \\
\hline Somewhat Satisfied & $40(37)$ & $13(21)$ \\
\hline $\begin{array}{c}\text { Neither Satisfied nor } \\
\text { Dissatisfied }\end{array}$ & $23(21)$ & $21(35)$ \\
\hline Not Very Satisfied & $6(5)$ & $9(15)$ \\
\hline Not at All Satisfied & $3(3)$ & $5(8)$ \\
\hline
\end{tabular}

Functional assessments were recorded in each trial. Linear range of motion (ROM) assessments of bilateral mobility in the neck and shoulder region were measured in degrees using a universal inclinometer. The Oswestry Disability Index (ODI) is a measure derived from the Oswestry Low Back Pain Questionnaire used by clinicians and researchers to quantify disability for acute or chronic low back pain. The ODI is currently considered the 
gold standard of low back functional outcome tools for measuring degree of disability and estimating quality of life in patients with low back pain [18]. The ODI is expressed as a percentage of the maximum score. Summary scores are interpreted as 0 to 20 (minimal disability), 21-40 (moderate disability), 41-60 (severe disability), 61-80 (crippling back pain), 81-100 (bed-ridden or exaggerated symptoms). Higher ODI \% total index scores are associated with greater disability and a $10 \%$ change is considered to be a clinically meaningful change in disability.

The Foot Function Index (FFI) is a self-administered questionnaire that measures the effect of foot pain on individual functioning in everyday life. The FFI questionnaire was completed at baseline, end of study treatment (Week 3) and study endpoint ( 2 weeks post-treatment). Scores are summed across all three subscales to produce a Total FFI score. A decreased score indicates reduced impact of heel pain on patient daily life.

\section{Statistical Analysis}

A t-test for two independent samples was used to evaluate the difference in mean changes in baseline VAS pain scores for subjects in the active and sham treatment groups. A Fischer's Exact
Test for two independent proportions was used to compare the difference in individual treatment successes between treatment groups. Change in Oswestry Disability Index (ODI) \% total score index scores were evaluated using analysis of covariance, with change from baseline to endpoint in ODI \% total index score as the dependent variable, baseline ODI \% total score index as the covariate and treatment group as a main effect. A one-way analysis of variance for four correlated samples was used to assess changes in mean total Foot Function Index (FFI) scores, and a subsequent Tukey HSD test was used to assess changes in mean Total FFI scores between various assessment points.

\section{Results}

\section{Pain Analysis}

Among subjects in the active treatment group, there was a $45.4 \%$ mean decrease in VAS scores compared to a $15.1 \%$ mean decrease among sham-treated subjects $(p<0.0001)$. These results are summarized in Figure 1. The 27.5-point mean decrease in VAS scores among subjects treated with active treatment devices was $>3$-fold greater than the 8. 7-point mean decrease in VAS scores among sham-treated subjects.

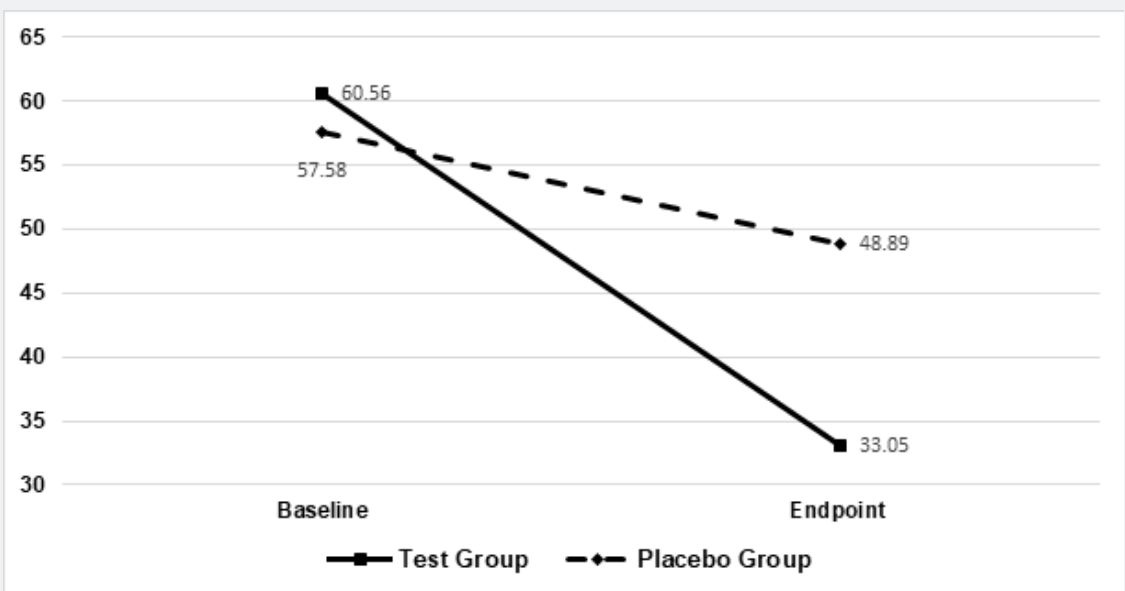

Figure 1: Change in Mean VAS Pain Ratings by Treatment Group.

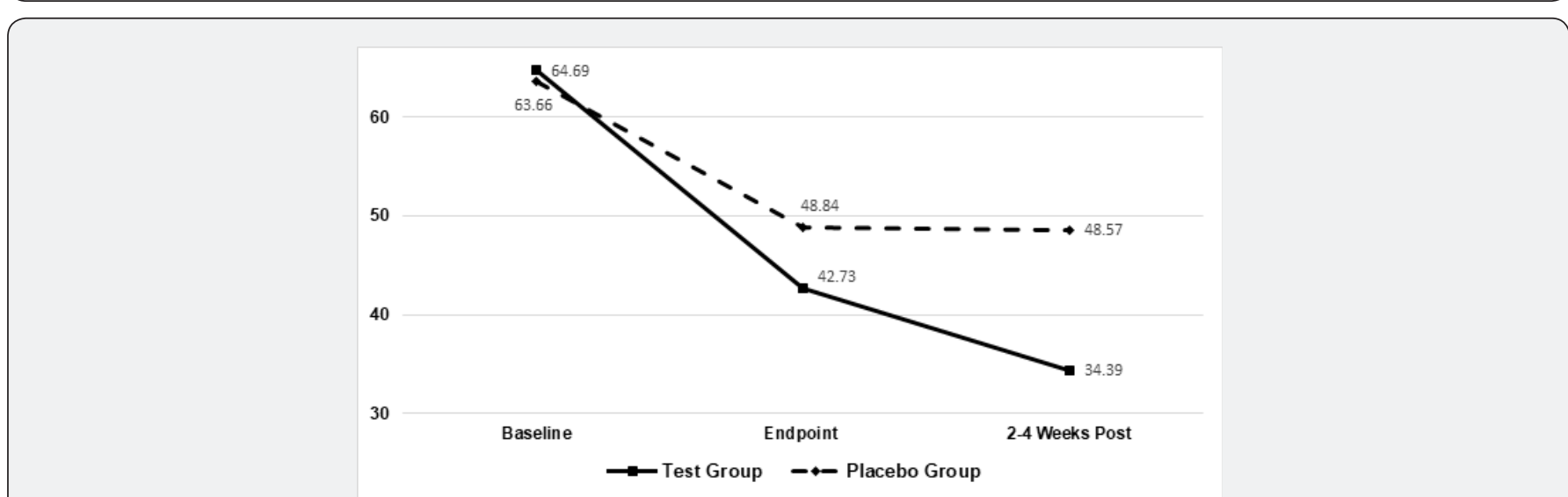

Figure 2: Change in Mean VAS Pain Ratings 2 to 4 Weeks Post-Treatment. 


\section{Proportion of Treatment Success}

Among subjects receiving active treatment, (69\%) achieved individual treatment success while among subjects receiving sham treatment $(27 \%)$ individual treatment success was achieved by subjects $(p<0.0001)$. This $42 \%$ difference exceeded the required $35 \%$ difference in individual success criteria between treatment groups.

\section{Data}

Figures $2 \& 3$ shows the mean change in baseline VAS pain scores 2 to 4 weeks and 2 to 4 months post-treatment for active- and sham-treated groups. Among subjects in the active treatment group, the mean VAS pain scores decreased an additional 19\% after 2 to 4 weeks following the last treatment while mean scores in the placebo group remained unchanged. Similarly, the mean VAS pain scores decreased an additional 33\% after 2 to 4 months following the last treatment of the Erchonia laser while mean scores in the placebo group had the opposite effect increasing 16\%. Two studies followed the active group 12 months from the last treatment, in which these subjects mean VAS pain scores decreased additional $56 \%$ and sustained improvement in disability indexes Figure 4.

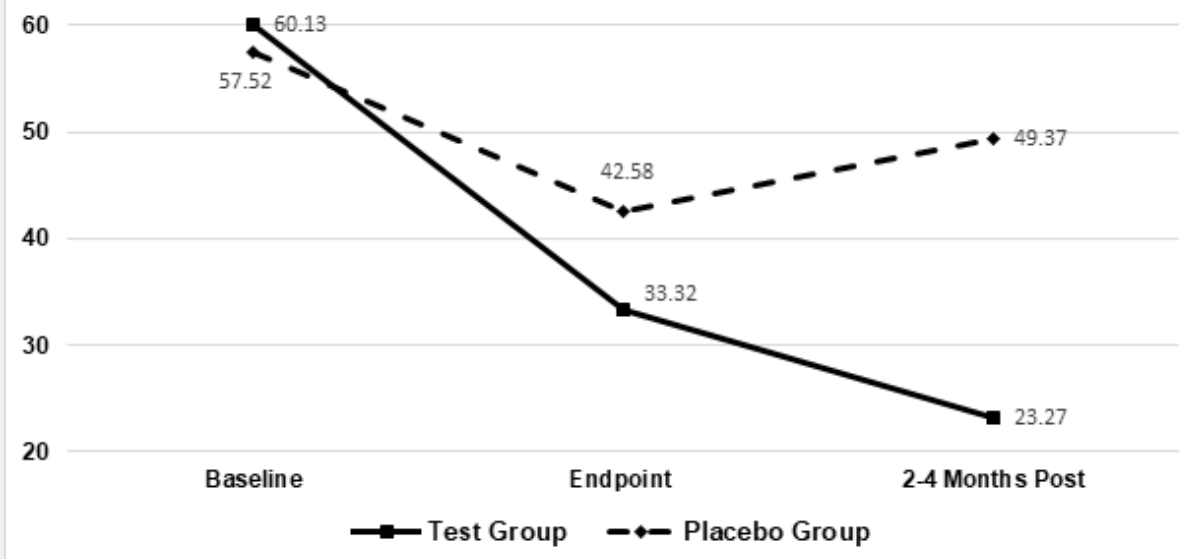

Figure 3: Change in Mean VAS Pain Scores 2 to 4 Months Post-Treatment.

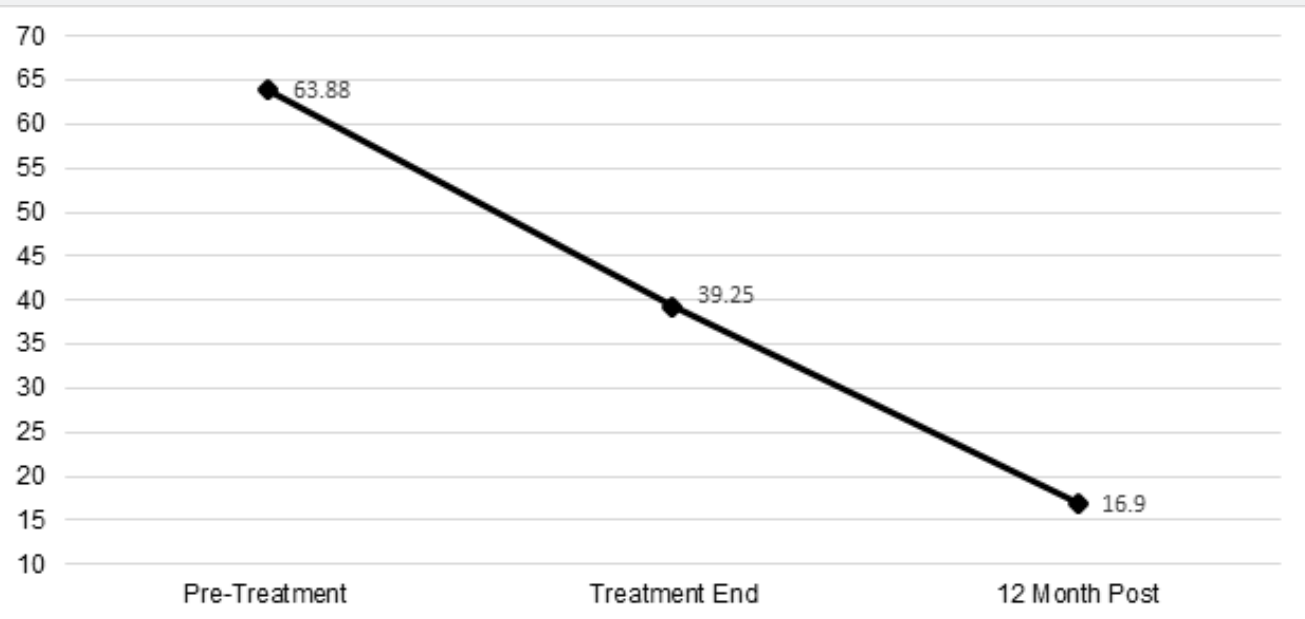

Figure 4: Change in Mean VAS Pain Scores Baseline to 12 Months Post-Treatment.

\section{Treatment Outcome Satisfaction}

Overall, $71 \%$ of subjects that received active treatment were satisfied with their treatment outcome. In contrast, only $42 \%$ of sham-treated subjects were satisfied. The proportion of subjects dissatisfied with active and sham treatment outcomes were $8 \%$ and $23 \%$, respectively.

\section{Functionality Assessments - Range of Motion}

Linear ROM assessments of bilateral mobility in the neck and shoulder region are summarized in Figure 5. Overall, there was a $>20 \%$ improvement in baseline ROM. 


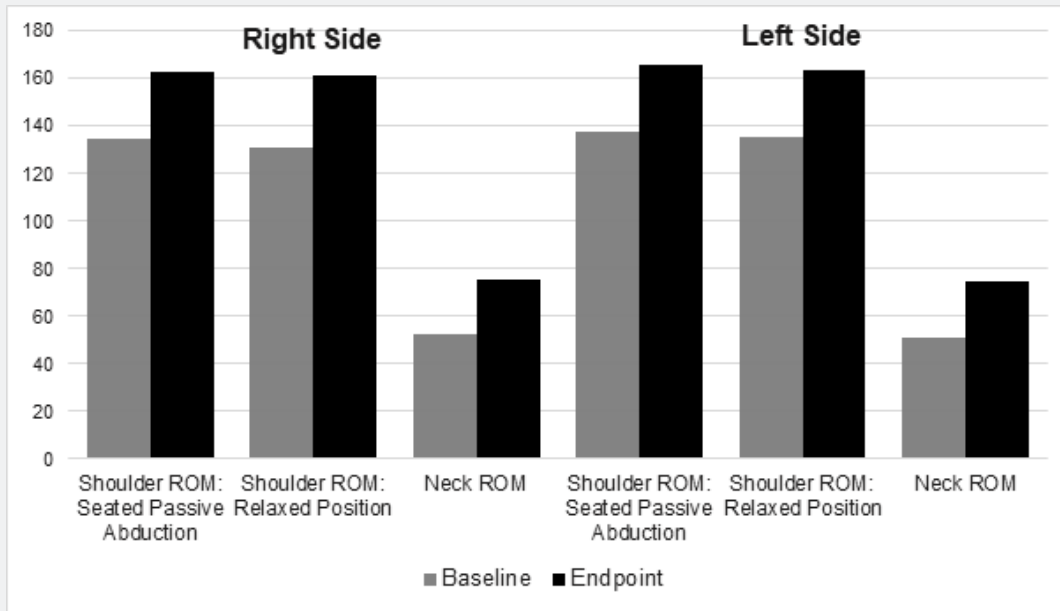

Figure 5: Change in Mean Baseline ROM Measurements.

\section{Functionality Assessments - ODI Change Scores}

The mean change in baseline ODI \% total index scores among subjects receiving active treatment $(-12.3)$ was substantially greater than the change for placebo-treated subjects $(-5.2)$ and were indicative of clinically meaningful improvement in disability. The overall change in ODI decreased from moderate to minimal disability. The change in mean ODI \% total index scores from baseline to post-procedure Week 8 is shown in Figure 6.

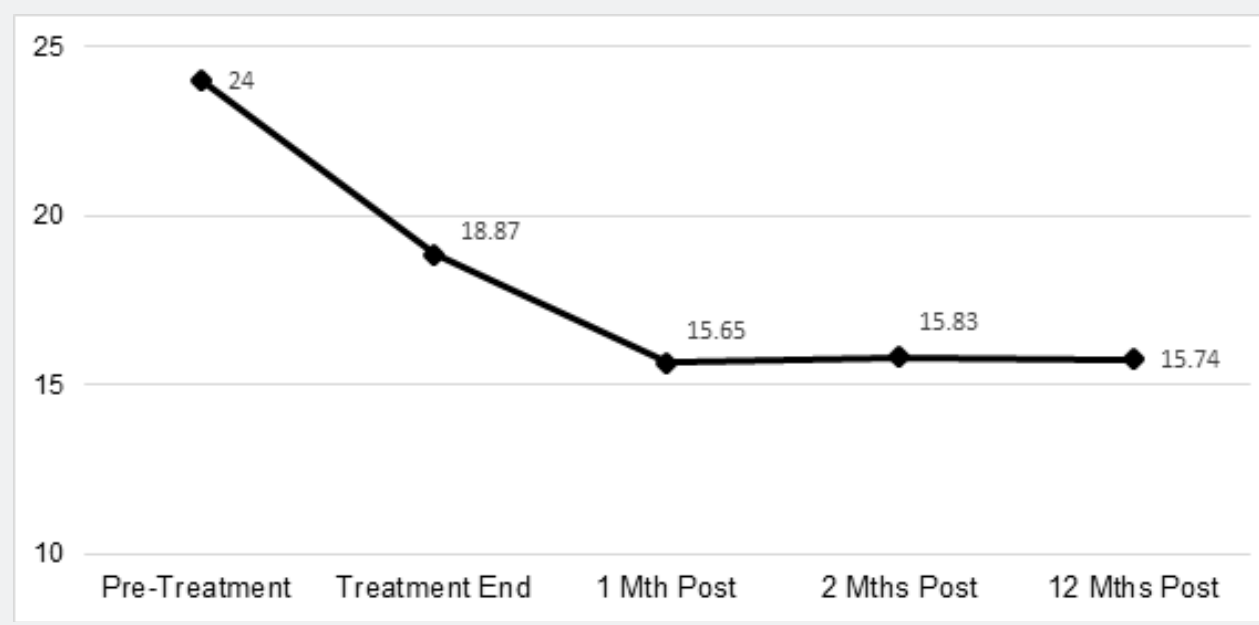

Figure 6: Change in Mean ODI Percent Total Scores.

\section{Foot Function Index}

The change in mean total FFI scores are shown graphically in Figure 7. There was a continued 65\% improvement in total FFI Score from study endpoint to 12 months post-treatment $(\mathrm{p}<0.0001)$. A Tukey HSD test revealed significant changes in mean total FFI scores at various time points:

- $\quad$ Baseline and Endpoint $(\mathrm{p}<0.05)$

- $\quad$ Baseline and 6 Months Post-Treatment $(\mathrm{p}<0.01)$

- $\quad$ Baseline and 12 Months Post-Treatment $(\mathrm{p}<0.01)$

- $\quad$ Endpoint and 6 Months Post-Treatment $(\mathrm{p}<0.01)$
- $\quad$ Endpoint and 12 Months Post-Treatment $(\mathrm{p}<0.01)$

Safety

There were no reports of adverse events for any study subject during the six clinical trials described in this study.

\section{Discussion}

The therapeutic effect of LLLT occurs through the process of photochemistry. The first law of photochemistry, known as the Grotthuss-Draper law, states that light must be absorbed by a chemical substance in order for a photochemical reaction to take place. This chemical change can also be defined as Laser 
Pharmacology ${ }^{\mathrm{TM}}$ which describes the discipline in which a series of interactions caused by Erchonia laser photons produce a change in physiology, through similar if not the same biological pathways of pharmaceutical drugs. The mechanism of action is completely nonthermal. The effects of laser light on biological signaling systems does not require deep penetration, as the cell membrane appears to be the primary absorber of the energy which then generates intracellular effects by means of a second messenger / cascade type response [19]. The Laser Pharmacology ${ }^{\mathrm{TM}}$ effect of the Erchonia $635 \mathrm{~nm}$ red laser, begins when a suitable molecule called a chromophore absorbs photons of an appropriate wavelength. The best-studied chromophore is cytochrome C oxidase (CCO) which contains two copper- and two heme-containing groups. $\mathrm{CCO}$ is found in the mitochondria where it can be stimulated by red laser light [20].

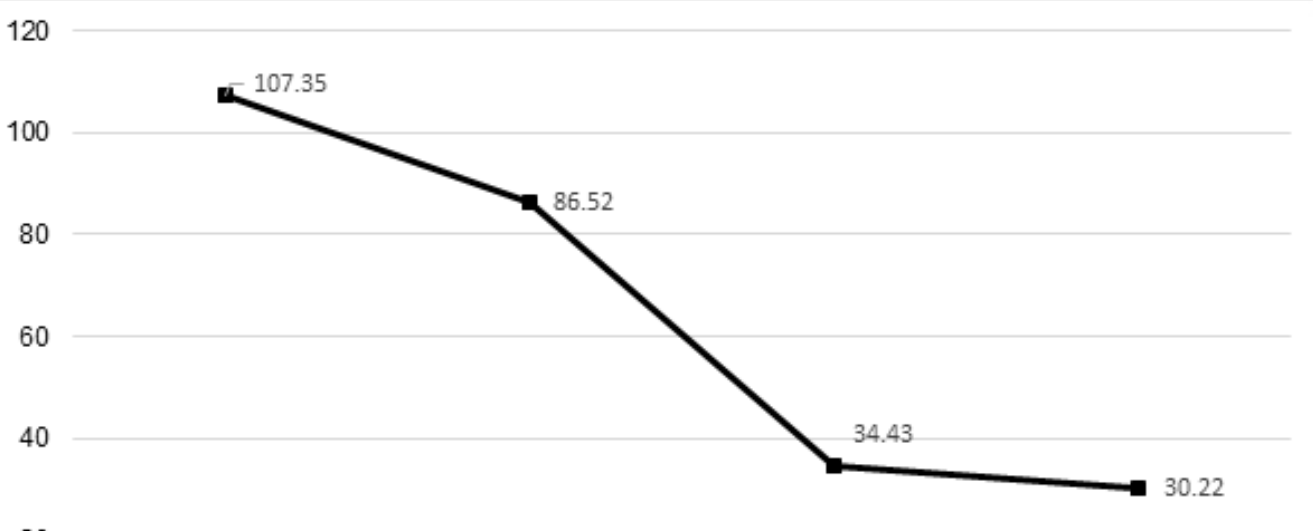

20

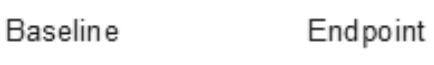

6 Months Post

12 Months Post

Figure 7: Long-Term Mean Total FFI Score.

This is significant because mitochondria are involved in a wide range of metabolic activity including regulating cell membrane potential, apoptosis, cell proliferation, heme and steroid synthesis [21]. Mitochondria are also intimately involved in signaling cascades between the mitochondrial reticulum and the rest of the cell, such as calcium signaling, GTPases, kinases and phosphatases [21]. Secondary mediators of photochemistry include reactive oxygen species (ROS), nitric oxide and cAMP which can also activate transcription factors and signaling pathways [20].

Irradiation of fibroblasts with $628 \mathrm{~nm}$ red light has been shown to produce the same biological effects as many NSAIDS, which include reduction prostaglandin $\mathrm{E}_{2}$, cyclooxygenase- 2 and tumor necrosis factor- $\alpha$ (TNF- $\alpha$ ) [22]. In addition, exposure to 628 $\mathrm{nm}$ red light increases expression of genes known to be involved in numerous cell functions including cell proliferation, antioxidation, metabolism, ion channel and membrane potential, cytoskeleton and extracellular matrix proteins, DNA synthesis and repair, transcription factors, immunity, inflammation and cytokines [22]. Inhibition of cyclooxygenase (Cox) and prostaglandin $\mathrm{E}_{2}\left(\mathrm{PGE}_{2}\right)$ protects cells against injury from inflammation and oxidative stress. An investigation studied the effect of Red 660nm LLLT on both COX-2 and COX-1 messenger RNA (mRNA) expression. Following exposure to LLLT there was a reduction in COX-2 mRNA expression both in the subplantar $(\sim 2.5$-fold $)$ and brain (4.84-9.67-fold) tissues. It is possible that the mechanism of LLLT decreasing hyperalgesia is also related to its effect in reducing the COX-2 expression in the CNS [23].

The beneficial effects of LLLT on TNF- $\alpha$ and transforming growth factor-beta (TGF- $\beta$ ) expression during the repair process has also been demonstrated in an animal model [24]. Rats were randomized into cryoinjury, cryoinjury treated with LLLT and uninjured control groups. LLLT consisted of three-weekly 10 -second sessions with a $660 \mathrm{~nm}$ laser. LLLT decreased TNF- $\alpha$ mRNA expression 1- and 7-days following injury and TGF- $\beta$ mRNA expression 7 days following injury comparison to the untreated group. Thus, while both NSAIDS and LLLT reduce TNF-a and COX-2, they do so by different means which may account for the superior safety profile of LLLT.

Another animal study assessed the impact of LLLT at visible wavelengths of 635,532 , and $405 \mathrm{~nm}$ on renal fibrosis in mice and their beneficial effects on mesenchymal stem cells (MSCs) [25]. All three wavelengths significantly synergized with MSC to enhance mitochondrial activity and reduce apoptosis 24 hours after exposure; however, each wavelength demonstrated different effects: combined treatment with the $532 \mathrm{~nm}$ laser and MSC increased proliferative activity in the renal cortex, endothelial proliferation increased following exposure to the $635 \mathrm{~nm}$ laser alone and $405 \mathrm{~nm}$ laser combined with MSC, and transforming growth factor-b (TGF- $\beta$ ) was reduced following exposure to 532 $\mathrm{nm}$ alone and when combined with MSC [25]. 
Other differences between NSAIDs and LLLT involve ROS. NSAIDs have been shown to induce ROS in different tissue cells, resulting in increased oxidized proteins which alter important intracellular signaling pathways which can lead to apoptosis and cell death [26]. LLLT also increases ROS generation which can induce transcriptional changes, and specifically activate the production of NF- $\kappa \mathrm{B}$ which regulates the beneficial immune response to inflammation [27]. Interestingly it is noted LLLT demonstrates a biphasic, drug-like dose response where low light levels have a positive effect on stimulating tissue repair while higher levels have a negative effect [28].

For LLLT to be effective, there are delivery fundamentals that must be met when applying the treatment. One basics is the distinct difference between lasers and the light generated by light-emitting diode (LED) devices. These are due to the different mechanisms by which light is produced by these devices [29]. The main property of laser light is its monochromatic nature, having only one wavelength. Light from LEDs cannot achieve the same narrow band of lasers and are referred to as quasimonochromatic. Laser devices generate coherent light, meaning the light is organized with the same frequency and the same waveform and is described as being "in phase." Highly coherent light rays can travel long distances without losing coherence. The light produced by a LED is disorganized or incoherent [30,31]. Laser light is collimated, meaning light rays are parallel and travel without divergence, or spreading. This is not true for LED light. These properties determine the effect of LLLT on biological systems which cannot be achieved by other light sources. Therefore, light from a $635 \mathrm{~nm}$ laser is dramatically more effective for producing photochemical effects than a 635nm LED which is evident by use of a 635nm LED as a sham control device in the referenced studies.

Additionally, it is crucial to distinguish the output power of the laser. To classify as Low-Level Laser therapy, the device output must be less than $500 \mathrm{mw}$ [32]. Devices with a laser output above $500 \mathrm{mw}$, are not LLLT instead classified as High intensity Laser (HIL) or Class 4 laser. These devices are FDA cleared under the ILY product code, Lamp, Infrared, Therapeutic heating [33]. The ILY category started as a heating pad and has expanded to thermal lasers, which are intended to "provide topical heating for the purpose of elevating tissue temperature for temporary relief of muscle and joint pain and stiffness, arthritis pain, or muscle spasm, the temporary increase in local blood circulation and/ or promoting relaxation of muscle". FDA has now made the ILY products $510(\mathrm{k})$ exempt based on the device requirements of raising skin temperature to $40-45^{\circ} \mathrm{C}$. The raise in temperature creates a concern as most proteins, DNA, RNA, membranes and their integral structures start to unwind or melt at temperatures ranging from $40-100^{\circ} \mathrm{C}$, the result is denaturation or loss of function ${ }^{43}$. The first mechanism by which tissue is thermally affected can be attributed to conformational changes of molecules. These effects, accompanied by bond destruction and membrane alterations are summarized in the single term hyperthermia ranging from approximately $42-50^{\circ} \mathrm{C}$. If such a hyperthermia lasts for several minutes, a significant percentage of the tissue will already undergo necrosis [34]. LLLT is a non-thermal process and classified under FDA product code NHN, powered lightbased laser non-thermal instrument with non-heating effect for adjunctive use in pain therapy [35]. Blinded and controlled trials are required for new $510(\mathrm{k})$ indications.

The laser wavelength determines the quality or type of interaction between the laser and the tissue. The lasers used in the referenced studies were $635 \mathrm{~nm}$ which is in the visible light spectrum. Another type of electromagnetic radiationisinfrared(IR) which includes wavelengths higher than $780 \mathrm{~nm}$ to invisible range $(1000 \mu \mathrm{m})$ [36]. While visible light can produce photochemical effects, infrared only produces molecular rotations and vibrations [21]. A systematic review was conducted to summarize the effects of Photo biomodulation on pain and disability in people with nonspecific low back pain, when: compared with control conditions (such as minimal intervention, placebo and no treatment) [37]. The systematic review included results from 12 trials, all of which applied laser with wavelengths in the Infrared spectrum, ranging from $808-1064 \mathrm{~nm}$. The results showed that there was low-quality evidence that the laser treatment was not better than sham for acute/subacute or chronic LBP in the short term. The authors concluded "current evidence does not support the use of PBMT to decrease pain and disability in people with non-specific LBP" [37]. A possible explanation is in biological tissue, either water molecules or macromolecules such as proteins and pigments mainly cause absorption. The absorption of infrared light can be attributed to water molecules, whereas UV and visible light absorbs by proteins and pigments [34]. Photochemical interaction mechanisms take place at very low power densities (typically $1 \mathrm{~W}$ $\mathrm{cm}$ ) and long exposure times ranging from seconds to CW lasers. In most cases, wavelengths in the visible range are used because of their high optical penetration depths [34].

Although NSAIDs are widely prescribed for treating musculoskeletal conditions, drug toxicity is a common problem. It may be especially troublesome among the $40 \%$ of people $\geq 65$ years old who are prescribed NSAIDs annually [38]. At one time, it was estimated more than 100,000 patients were hospitalized annually for NSAID-related GI complications alone with significant mortality and a medical cost exceeding \$4 billion. 42 Other drug therapies for low back pain include benzodiazepines, antidepressants, opioids, skeletal muscle relaxants and systemic corticosteroids; however, the overall effects on pain reduction and improvement of function are generally small to moderate and of short-duration $[39,40]$.

The use of opioids is not superior to nonopioid medications for moderate to severe chronic back pain, or hip and knee osteoarthritis pain and does not improve pain-related function 
or patient quality of life [41]; nevertheless, the widespread use of opioids for treating pain has resulted in the current opioid epidemic. Fortunately, the numbers of prescriptions for opioid medications appears to be decreasing [42]. Based on the safety and efficacy of this review evaluating four hundred and nineteen (419) subjects and various anatomical areas, $635 \mathrm{~nm}$ laser therapy with appropriate power and dose should be consider the first line of treatment for individuals suffering from nociceptive musculoskeletal pain.

\section{Acknowledgment}

The authors acknowledge the editorial assistance of Dr. Carl S. Hornfeldt, Apothekon, Inc., during the preparation of this manuscript. The studies were sponsored by Erchonia Corporation, Melbourne, FL. As the study sponsor, Erchonia was responsible for device setup and training. The studies were performed at an independent physician sites, which completed CITI training (Collaborative Institutional Training Initiative) and approved through the Western Institutional Review Board (WIRB).

\section{References}

1. World Health Organization (2019) Musculoskeletal conditions.

2. Yelin EH CM, Watkins-Castillo SI (2020) The Burden of Musculoskeletal Diseases in the United States. Prevalence, Societal and Economic Cost, Fourth Edition, 2020.

3. Gaskin DJ, Richard P (2012) The economic costs of pain in the United States. J Pain 13(8): 715-724.

4. Kuritzky L, Samraj GP (2012) Nonsteroidal anti-inflammatory drugs in the treatment of low back pain. J Pain Res 5: 579-590.

5. Walker BF (2000) The prevalence of low back pain: a systematic review of the literature from 1966 to 1998. J Spinal Disord 13(3): 205-217.

6. Enthoven WT, Roelofs PD, Deyo RA, van Tulder MW, Koes BW (2016) Non-steroidal anti-inflammatory drugs for chronic low back pain. Cochrane Database Syst Rev 2: CD012087.

7. Varga Z, Sabzwari SRA, Vargova V (2017) Cardiovascular risk of nonsteroidal anti-inflammatory drugs: an under-recognized public health issue. Cureus. 9: e1144.

8. Yuan JQ Tsoi KK, Yang M, J Y Wang, D E Threapleton, et al. (2016) Systematic review with network meta-analysis: comparative effectiveness and safety of strategies for preventing NSAID-associated gastrointestinal toxicity. Aliment Pharmacol Ther. 43(12): 1262-1275.

9. US National Library of Medicine, National Institutes of Health (2014) Low level laser light therapy and chronic neck and shoulder pain. ClinicalTrials.gov Identifier: NCT00929305.

10. US National Library of Medicine (2016) National Institutes of Health Study of low-level laser therapy to treat low back pain. ClinicalTrials. gov Identifier: NCT01835756.

11. US National Library of Medicine, National Institutes of Health (2014) Study of low-level laser therapy to treat chronic heel pain arising from plantar fasciitis. ClinicalTrials.gov Identifier: NCT01835743.

12. US National Library of Medicine, National Institutes of Health. Low level laser therapy to reduce chronic pain. ClinicalTrials.gov Identifier: NCT00929773.
13. Silverman RG, Comey A, Sammons T (2019) Effects of a single treatment with two nonthermal laser wavelengths on chronic neck and shoulder pain. Med Devices (Auckl) 12: 319-325.

14. Jastifer JR, Catena F, Doty JF, Stevens F, Coughlin MJ (2014) Lowlevel laser therapy for the treatment of chronic plantar fasciitis: a prospective study. Foot Ankle Int. 35(6): 566-571.

15. Roche GC, Murphy DJ, Berry TS, Shanks S (2016) Low-level laser therapy for the treatment of chronic neck and shoulder pain. Funct Neurol Rehabil Ergon 6: 97-104.

16. Trevor S Berry, Paul J Quarneri, Gregory Roche (2020) A Randomized, Double-Blind, Sham-Controlled Study Evaluating the Effectiveness of a Low-level Laser Device for Treating Lower Back Pain. eMedical 2: 100005

17. Hawker GA, Mian S, Kendzerska T, French M (2011) Measures of adult pain: Visual Analog Scale for Pain (VAS Pain), Numeric Rating Scale for Pain (NRS Pain), McGill Pain Questionnaire (MPQ), ShortForm McGill Pain Questionnaire (SF-MPQ), Chronic Pain Grade Scale (CPGS), Short Form-36 Bodily Pain Scale (SF-36 BPS), and Measure of Intermittent and Constant Osteoarthritis Pain (ICOAP). Arthritis Care Res (Hoboken) 11: S240-252.

18. Fairbank JC, Pynsent PB (2000) The Oswestry Disability Index. Spine (Phila Pa 1976) 25(22): 2940-2952.

19. International Society for Electrophysical Agents in Physical Therapy (ISEAPT); Low Intensity Laser Therapy - LILT : Low Level Laser Therapy. Electrotherapy.

20. Hamblin MR (2018) Mechanisms and mitochondrial redox signaling in photobiomodulation. Photochem Photobiol 94(2): 199-212.

21. Smith KC (2010) Molecular targets for low level laser therapy. Laser Therapy 3: 135-142.

22. Zhang Y, Song S, Fong CC, Tsang CH, Yang Z, et al. (2003) cDNA microarray analysis of gene expression profiles in human fibroblast cells irradiated with red light. J Invest Dermatol 120: 849-857.

23. Prianti AC Jr, Silva JA Jr, Dos Santos RF, Rosseti IB, Costa MS (2014) Low-level laser therapy (LLLT) reduces the COX-2 mRNA expression in both subplantar and total brain tissues in the model of peripheral inflammation induced by administration of carrageenan. Lasers Med Sci 29(4): 1397-403.

24. Mesquita-Ferrari RA, Martins MD, Silva JA Jr, Tatiana Dias da Silva, Roberto Farina Piovesan, et al. Effects of low-level laser therapy on expression of TNF- $\alpha$ and TGF- $\beta$ in skeletal muscle during the repair process. Lasers Med Sci 26(3):335-340.

25. O'Connor M, Patil R, Yu J, Richard Hickey, Kavitha Premanand, et al. (2016) Mesenchymal stem cells synergize with 635, 532, and $405 \mathrm{~nm}$ laser wavelengths in renal fibrosis: a pilot study. Photomed Laser Surg 34(11): 556-563.

26. Ghosh R, Alajbegovic A, Gomes AV (2015) NSAIDs and cardiovascular diseases: role of reactive oxygen species Oxid Med Cell Longev 2015: 536962 .

27. Zhang J, Xing D, Gao X (2008) Low-power laser irradiation activates Src tyrosine kinase through reactive oxygen species-mediated signaling pathway. J Cell Physiol 217(2): 518-528.

28. Huang Y-Y, Chen AC-H, Carroll JD, Hamblin MR (2009) Biphasic dose response in low level light therapy. Dose Response 7(4): 358-383.

29. Heiskanen V, Hamblin MR (2018) Photobiomodulation: lasers vs. light emitting diodes? . Photochem Photobiol Sci 17(8): 1003-1017.

30. Moskvin SV (2017) Only lasers can be used for low level laser therapy. Biomedicine (Taipei) 7(4): 22. 
31. Kumar J (2010) Coherence length of a light-emitting diode (LED). Lab Experiments 10: 1-13.

32. Low Level Laser Therapy (2020) Physiopedia 19: 59.

33. https://www.accessdata.fda.gov/scripts/cdrh/cfdocs/cfPCD/ classification.cfm?ID=ILY

34. Mohammed M Jawad, Sarah T Abdul Qader, AA Zaidan, BB Zaidan, AW Naji Ibraheem T (2011) Abdul Qader, 2011. An Overview of Laser Principle, Laser-Tissue Interaction Mechanisms and Laser Safety Precautions for Medical Laser Users. International Journal of Pharmacology 7: 149-160.

35. https://www.accessdata.fda.gov/scripts/cdrh/cfdocs/cfPCD/ classification.cfm?ID=NHN

36. Tsai SR, Hamblin MR (2017) Biological effects and medical applications of infrared radiation. J Photochem Photobiol B 170: 197.

37. Shaiane Silva Tomazoni, Matheus Oliveira Almeida, Jan Magnus Bjordal, Martin Bjørn Stausholm, Caroline dos Santos Monteiro Machado, et al. (2020) Photobiomodulation therapy does not decrease pain and disability in people with non-specific low back pain: a systematic review. Journal of Physiotherapy Volume 66(3): 155-165.
38. Marcum ZA, Hanlon JT (2010) Recognizing the risks of chronic nonsteroidal anti-inflammatory drug use in older adults. Ann Longterm Care 18(9): 24-27.

39. Bidaut-Russell M, Gabriel SE (2001) Adverse gastrointestinal effects of NSAIDs: consequences and costs. Best Pract Res Clin Gastroenterol 15(5): 739-753.

40. Chou R, Deyo R, Friedly J, Andrea Skelly, Melissa Weimer, et al. (2017) Systemic pharmacologic therapies for low back pain: a systematic review for an American College of Physicians Clinical Practice Guideline. Ann Intern Med 166(7): 480-492.

41. Krebs EE, Gravely A, Nugent S, Agnes C Jensen, Beth DeRonne et al. (2018) Effect of opioid vs nonopioid medications on pain-related function in patients with chronic back pain or hip or knee osteoarthritis pain: the SPACE randomized clinical trial. JAMA 319(9): 872-882.

42. Manchikanti L, Helm S $2^{\text {nd }}$, Fellows B, Jeffrey W Janata, Vidyasagar Pampati, et al. (2012) Opioid epidemic in the United States. Pain Physician 15: ES9-38.

\section{Your next submission with Juniper Publishers will reach you the below assets}

- Quality Editorial service

- Swift Peer Review

- Reprints availability

- E-prints Service

- Manuscript Podcast for convenient understanding

- Global attainment for your research

- Manuscript accessibility in different formats ( Pdf, E-pub, Full Text, Audio)

- Unceasing customer service

Track the below URL for one-step submission https://juniperpublishers.com/online-submission.php 